\title{
Associated Persons Reproductive System Findings Domain
}

National Cancer Institute

\section{Source}

National Cancer Institute. Associated Persons Reproductive System Findings Domain. NCI Thesaurus. Code C147176.

A domain utilized for the submission of reproductive system findings records related to persons associated with the study subject. 